CARPATHIAN JOURNAL OF FOOD SCIENCE AND TECHNOLOGY

journal homepage: http://chimie-biologie.ubm.ro/carpathian_journal/index.html

\title{
EFFECT OF ADDITION OF WHEAT AND PIGEON-PEAN ON THE RHEOLOGICAL CHARACTERISTICS OF RICE FLOUR
}

\author{
Olugbenga Olufemi Awolu ${ }^{1,2}$ * \\ ${ }^{I}$ Department of Food Engineering, CSIR-Central Food Technological Research Institute, Mysore 570020 \\ ${ }^{2}$ Department of Food Science and Technology, Federal University of Technology, Akure, Nigeria \\ *ooawolu@futa.edu.ng
}

https://doi.org/10.34302/crpjfst/2019.11.3.5

Article history:

Received:

2 January 2019

Accepted:

28 May 2019

Keywords:

Amylograph;

Dynamic rheology;

Pasting characteristics;

Pigeon-pea flour;

Rice flour

Wheat.

\section{ABSTRACT}

Evaluation of the pasting characteristics, dough mixing properties and dynamic rheology of composite flour comprising wheat, rice and pigeonpeas flours was carried out in order to determine suitability of the composite flour for some bake products production. The pasting characteristics, dough mixing properties and dynamic rheology were evaluated using amylograph, farinograph and rheometer respectively. The blend with wheat and rice flour only had zero breakdown viscosity at $50 \%$ wheat $/ 50 \%$ rice flour and $30 \%$ wheat $/ 70 \%$ rice flour while $100 \%$ wheat flour had the highest breakdown viscosity of $167 \mathrm{BU}$. However, wheat/rice flour blends had the highest setback viscosity, meaning it will enhance starch retrogradation most. Addition of pigeon-pea reduced the setback viscosity (347-376 BU) compared to $100 \%$ wheat flour (387 BU). The 50\%:50\% wheat-rice flour blend had the highest ( $802 \mathrm{BU}$ ) final viscosity followed by $100 \%$ wheat flour (746 BU) while 100\% wheat flour had the best pasting temperature and peak viscosity. Inclusion of pigeon-pea flour to rice-wheat blends produced mixing quality close to $100 \%$ wheat flour in terms of dough constitency and water absorption. The stability of the blends with pigeon-pea was better than $100 \%$ wheat flour. Blend, $30 \%$ wheat $/ 70 \%$ rice flour had poor mixing quality. Addition of pigeon-pea enhanced mixing quality and the dynamic rheology properties ( $\mathrm{G}^{\prime}, \mathrm{G}^{\prime \prime}$, shear stress vs shear rate) of the blends.

\section{Introduction}

Rice (Oritza sativa) is a staple food of consumed by over approximately half of the world's population (Ahmed et al., 2015). Rice flour is gluten-free, hence, a good source of flour for people who are gluten intolerant (Helms. 2005). Rice flour has been described as a viable alternative to wheat flour in the production of baked products (Martínez et al., 2014; de la Hera et al., 2013). Several researches have been carried out using rice in the production of extruded products (Awolu et al., 2015; Martínez et al., 2014), bread production (Nozawa et al., 2016; Araki et al., 2016; Therdthai et al., 2016), and cookies (Rai et al., 2014). The search for viable alternative to wheat flour and development of composite flour has several objectives such as the need to diversify wheat utilization, cost effectiveness, health purposes especially for people who are gluten intolerant (Awolu et al., 2017). A more formidable reason is the development of functional baked products which will be nutritionally enriched with protein, fibre and antioxidants (Awolu et al., 2017; Awolu et al., 2016).

The major problem with the development of composite flours without wheat has been the inability of the composite flour to have proper viscoelastic behaviour suitable for bread production in particular. So the many researches 
were aimed at improving the rheological characteristics of the composite flours, or ricebase flours. Several approaches are being adopted to enhance the rheological properties of non-wheat composite flour, including but not limited to addition of hydrocolloids (Awolu, 2017), starch (Awolu and Oseyemi, 2016), fibre (Awolu et al., 2016), legumes. Addition of fibre and legumes have particularly gained interests because in addition to improving the rheological characteristics of the dough, it enhanced its nutritional properties by improving its protein, fibre and antioxidant contents (Marco and Rosell, 2008). In fact, the addition of legumes enhanced minerals contents, protein contents and antioxidant contents of the flour blends.

Pigeon-pea (Cajanuscajan) is an underutilized legume widely grown. It is has rich protein content up to about $26 \%$ (Oshodi et al., 1985) and also rich in fibre and mineral contents (Fasoyiro et al., 2010). It serves as a viable alternative to many rural dwellers especially in the tropics and subtropical regions where it is widely grown and affordable (Fasoyiro et al., 2010). Its utilization has been limited because of the presence of antinutrients and difficulty in cooking (Nene et al., 1990). However, effective processing had been successful at reducing such antinutrients to safe levels (Awolu et al., 2015)

Rheological properties are vital in the analysis of flow conditions in product processes as well as in the prediction of product stability (Wang et al., 2016; Li et al., 2014). It has been stablished to have direct relationship with textural attributes, which in turn affect the sensory characteristics and consumer acceptability of the products (Li et al., 2014). Small oscillatory frequency sweep using rheometer had been found to be extremely sensitive to the structure information of samples thereby making it useful in the evaluation of gelation behavior and kinetics (Liu et al., 2015).

The aim of this study is to explore various rheological measurement techniques, precisely rheometer and farinograph to evaluate the rheological properties of composite flour consisting wheat, rice and pigeon-pea flours. The effect of heating and shearing on the composite flour starch will also be explored by using viscoamylograph. The best blend in terms of rheological and pasting characteristics will be determined considering rice-wheat flour blend only, and also rice-wheat-pigeon pea flour blends; thereby establishing the effect of the addition of pigeon-pea on the blend rheology.

\section{Materials and methods}

\subsection{Materials}

Whole wheat flour $(9.1 \%$ moisture content, $11.0 \%$ protein and $13.9 \%$ dietary fibre) by Avent Agro Pvt. Ltd, Narela, Delhi 110040, India, was sourced from Mysore, India. Rice grains (Superior) and Pigeon-pea were sourced from Mysore, India.

\subsection{Preparation of rice flour}

Rice flour was prepared using the method adopted by Awolu et al. (2015). The rice grains (1 kg) were sorted, washed, oven-dried and milled into flour using hammer mill (Model: $\mathrm{CMC}=\mathrm{CM}-\quad \mathrm{Q}=753=97, \quad \mathrm{M}=\mathrm{s} \quad$ Cadmach Machinery Company) It was later passed through $0.037 \mathrm{~mm}$ test sieve (Jayant Test Sieves, Bombay, India).

\subsection{Preparation of pigeon-pea flour}

Pigeon-pea grains were soaked in hot water for 15 min, dehulled manually, and oven-dried at 65 $\mathrm{oC}$ for $24 \mathrm{~h}$. It was milled using hammer mill as described above, sieved using $0.037 \mathrm{~mm}$ test sieve (Jayant Test Sieves, Bombay, India) (Fasoyiro et al., 2010, modified).

\subsection{Blends formulation}

The blend formulation for rice, wheat and pigeon-pea flours are presented in Table 1.

\subsection{Pasting characteristics}

The pasting characteristics were determined by using Micro-Visco-Amylograph (model 803201 by Brabender, Germany). About $10 \mathrm{~g}$ of the samples were mixed with appropriate water as obtained from the instrument after inputting the 
moisture content. The sample was placed inside the amylograph and allowed to run for about 25 $\min$.

\subsection{Dough Rheological}

\subsubsection{Farinograph}

The farinograph evaluation was carried out according to the standard AACC (2000) methods. The amount of water added was generated by inputting the moisture content of the composite flour into the farinograph (Model: E-380, Brabender OHG, Duisburg, Germany) system and allowed to run for about $30 \mathrm{~min}$. Parameters measured include water absorption, dough development time, dough stability and mixing tolerance index.

\subsubsection{Dynamic rheology}

The dynamic rheology was carried out by using modified method of Demirkesen et al. (2010). The composite flour was carried out by using Modular Compact Rheometer (NCR52, Anton Paar). The position was set at $2.000 \mathrm{~mm}$, temperature at $25.00 \mathrm{oC}$ while the measuring system was PP76. The dough samples (without yeast) were placed between the parallel plates and the edges were carefully trimmed with a spatula. The flow experiments were carried out under steady-shear condition (Shear rate ranged from 1 to 50 1/s) while for the frequency sweep test, the strain rate was kept constant below $0.5 \%$; the dough elastic modulus and complex viscosity were measured as a function of frequency (between 0.1 and $100 \mathrm{rad} \mathrm{s}^{-1}$ )

\section{Results and discussions}

\subsection{Pasting characteristics}

The results of the pasting characteristics of the composite blends are shown in Fig. 1. Pasting characteristics represents the behaviour of the composite flour starch to heating and cooling. The $100 \%$ wheat flour had the best pasting temperature $(65.5 \mathrm{oC})$ and peak viscosity (521 BU). The flour blend with pigeon-pea flour had lower pasting temperature than blends with only rice-wheat blends. Wheatrice flour blend (50:50) performed better than blends with pigeon-pea in all pasting parameters measured except for the setback viscosity. The blend with $70 \%$ rice flour, however, had the least pasting quality. So, rice flour up to $50 \%$ could be recommended for flour blends requiring good pasting property. The challenge of setback viscosity of the wheat-rice flour blends could be solved by the incorporation of pigeon-pea flour. The samples with pigeon-pea had the least set back viscosities (347 and 376 BU for $20 \%$ and $10 \%$ pigeon pea incorporation respectively). The values were lower than what was obtained for $100 \%$ wheat flour (387 BU). The pasting temperature represents the temperature at which the viscosities first increase by at least 2 RVU over $20 \mathrm{~s}$ periods (Adegunwa et al., 2012). It is the minimum temperature at which starch granules in the flour swells (Awolu, 2017). The peak viscosity represents the pastes strength from gelatinization; it is the maximum viscosity attained during cooking (Adebowale et al., 2011). The holding strength measures of ability of granules to remain undisrupted during holding at high temperature (92 oC) and high mechanical shear stress (Adegunwa et al., 2012). A lower breakdown viscosity is required, as it signifies a higher stability.

An increase in viscosity as the temperature reduced from $92 \mathrm{oC}$ to $50 \mathrm{oC}$ is a reflection of the ability of the elements in pastes to associate as the paste temperature drops (Ocloo et al., 2010). This increase in viscosity is the setback viscosity. Setback viscosity corresponds to retrogradation

\subsection{Farinograph}

The results of the farinograph are shown in Fig. 2. Farinograph method has been described as the leading standard tool for rheological behaviour assessment of flour during bread dough development and mixing processes (Miś, et al., 2017). It measures dough resistance to the mixing blades during a prolonged and gentle mixing action at constant temperature. The dough development time (DDT) of $100 \%$ wheat flour (sample 1) dough was $3.16 \%$ while that of 
sample 3 (50\% wheat $/ 30 \%$ rice $/ 20 \%$ pigeon pea composite flour) was $9.14 \%$. The other samples had DDT ranged from 19.10 to $19.57 \%$. DDT is an indication of the dough mixing time. Sample 1 had the best DDT, followed by sample 3 . Inclusion of pigeon pea (a legume) at $20 \%$ (sample 3) improved not only the DDT but the entire farinograph parameters of the samples. Other parameters that distinctively reflected the inclusion of pigeon pea were dough stability, mixing tolerance index (MTI), farinograph quality numbers, time to breakdown which were $2.48 \mathrm{~min}, 93 \mathrm{FU}, 48 \mathrm{~mm}, 4.47 \mathrm{~min}$ and $7.45 \mathrm{~min}$, $37 \mathrm{FU}, 133 \mathrm{~mm}, 13.17 \mathrm{~min}$ for samples 1 and 3 respectively. There were no dough stability, mixing tolerance index (MTI), farinograph quality numbers and time to breakdown for samples 2, 4 and 5. While samples 2 and 5 consisted of only wheat and rice flour blends (between 30 and 50\% wheat flour inclusion), sample 4 had $10 \%$ pigeon pea flour added to wheat and rice flours. These results showed that the promotion of rice flour as a viable alternative to wheat flour for bread production may not be viable afterall, except where the amount of wheat flour inclusion is above $50 \%$, or addition of legumes and hydrocolloids to enhance the rheological characteristics of rice flour. Awolu and Oseyemi (2016) had shown that inclusion of wheat flours up to $72 \%$ to wheat-cocoyambambara groundnut composite flour produced farinograph properties that are very close to $100 \%$ wheat flour.

Low mixing tolerance index (MTI) and longer stability is preferred; sample 3 is better in terms of stability and MTI. Flours with low MTI have been reported to possess good tolerance to mixing, while flours with high MTI's were reported to be critical to mixing and overmixing in particular

The dough constitency for samples $1,2,3$, 4 and 5 were 522, 552, 574, 594 and $406 \mathrm{FU}$ respectively. The water absorption of sample 1 was 76\%, samples 3 and 4 had 64.8 and $65.3 \%$ water absorption respectively. The water absorption of samples 2 and 5 were 61.3 and $57.0 \%$ respectively. Optimum water absorption for bread making had been reported to be between 50 and 64\% (Mailhot and Patton, 1988), and it was found out that high water absorption is an indication of good baking performance (Zecevic et al., 2013). Awolu, et al. (2016) reported water absorption of $66.7 \%$ for composite flour consisting $72 \%$ wheat/19\% cocoyam/9\% bambara groundnut.

\subsection{Dynamic rheology}

The results showing the effects of shear stress and against shear rate (Fig, 3a to 7a), viscosity against strain (Fig, $3 \mathrm{~b}$ to $7 \mathrm{~b}$ ) and modulus against frequency (Fig, $3 c$ to $7 \mathrm{c}$ ) are shown. All the samples showed shear-thinning (pseudoplastic) behaviour except for $100 \%$ rice flour dough (Fig. 8a). The same behaviour was also replicated in Fig, $3 b$ to $7 \mathrm{~b}$. However, sample 1 had the highest initial viscosity (above 80,000 mPa.s) when considering samples 1 to 5 , while sample 3 distantly followed (just above 10, 000 mPa.s). Sample 2 with $50 \%$ wheat flour and $50 \%$ rice flour had initial viscosity of about $9,000 \mathrm{mPa}$.s. The reason for the decrease in viscosity of shear-thinning fluid had been deduced to the break down in interaction between flour components under the action of shear (Deirmikesen, et al., 2010). Similar result was reported by Deirmikesen, et al. (2010) when the rheological properties of rice bread dough containing different gums with or without emulsifiers were determined. For pseudoplastic fluid, viscosity was high at low strains and dough structure seems to be intact; high strain, however, lead to the disorganization and destruction of the dough's structure leading to reduced viscosity (Weipert, 1990). In essence, Figures $3 \mathrm{~b}$ to $7 \mathrm{~b}$ indicated that samples 2 to 4 may not perform favourably with sample 1 in the terms of dough rheology. However, sample with $100 \%$ rice flour (Fig. 8b) had a very high viscosity which does not translate into better dough rheological characteristics.

The viscoelastic properties of samples (fig. $3 \mathrm{c}$ to $7 \mathrm{c}$ ) showed that the samples displayed more viscous-like behaviour, with loss modulus greater than storage modulus. Such behaviour 
had been reported for wheat flours (Autio et al., 2001) and gluten-free dough (Ronda et al., 2013; Lazaridou et al., 2007) as a result of dilution of constituents (Mancebo et al., 2015); reduction in dough water level had been found to reverse the trend by increasing the storage modulus (Mancebo et al., 2015), making the dough to be more elastic-like. Addition of fibre (pysillium) and thickening agents (like HPMC) had been discovered to reduce the water content, and hence, increase the storage modulus (Mancebo et al., 2015). However, bread dough had been reported to exhibit shear-thinning and thixotropic behaviour (Weipert, 1990; Muller, 1975).

Wheat flour (100\%) as indicated by had the highest modulus while considering wheat-based composite flour (Fig. 3c to 7c), with G" greater than $G^{\prime}$. With increase in strain, the $G^{\prime \prime}$ was getting closer to $\mathrm{G}^{\prime}$, a tendency to be more elastic-like. All samples containing wheat displayed this behaviour. In terms of modulus magnitude, sample 2 and 3 were similar and close, while samples 4 and 5 were also similar and close. Samples 2 and 3 also had similar complex viscosity $(\eta)$ behaviour while samples 4 and 5 had similar complex viscosity behaviour. Rice $(100 \%)$ dough had greater $\mathrm{G}^{\prime \prime}$ than $\mathrm{G}^{\prime}$, which was an indication of elastic-like dough (Fig. 8). It could not, however, be said to possess good dough property. A wheat variety (Okapi) displayed behaviour similar to $100 \%$ rice dough with high $\mathrm{G}^{\prime}$ and low $\mathrm{G}^{\prime \prime}$, while the difference between the two were high (hence, low loss tangent) had been reported to reflect rigid and stiff material with a lower dough processing value (Weipert, 1990).

Table 1. Blends Formulation for Rice, Wheat and Pigeon-Pea Flours

\begin{tabular}{|l|l|l|l|}
\hline Sample & Wheat flour $(\mathrm{g} / 100 \mathrm{~g})$ & Rice flour $(\mathrm{g} / 100 \mathrm{~g})$ & Pigeon-pea flour $(\mathrm{g} / 100 \mathrm{~g})$ \\
\hline $\mathbf{1}$ & 100.0 & - & - \\
\hline $\mathbf{2}$ & 50.0 & 50.0 & - \\
\hline $\mathbf{3}$ & 50.0 & 30.0 & 20.0 \\
\hline $\mathbf{4}$ & 50.0 & 40.0 & 10.0 \\
\hline $\mathbf{5}$ & 30.0 & 70.0 & - \\
\hline
\end{tabular}

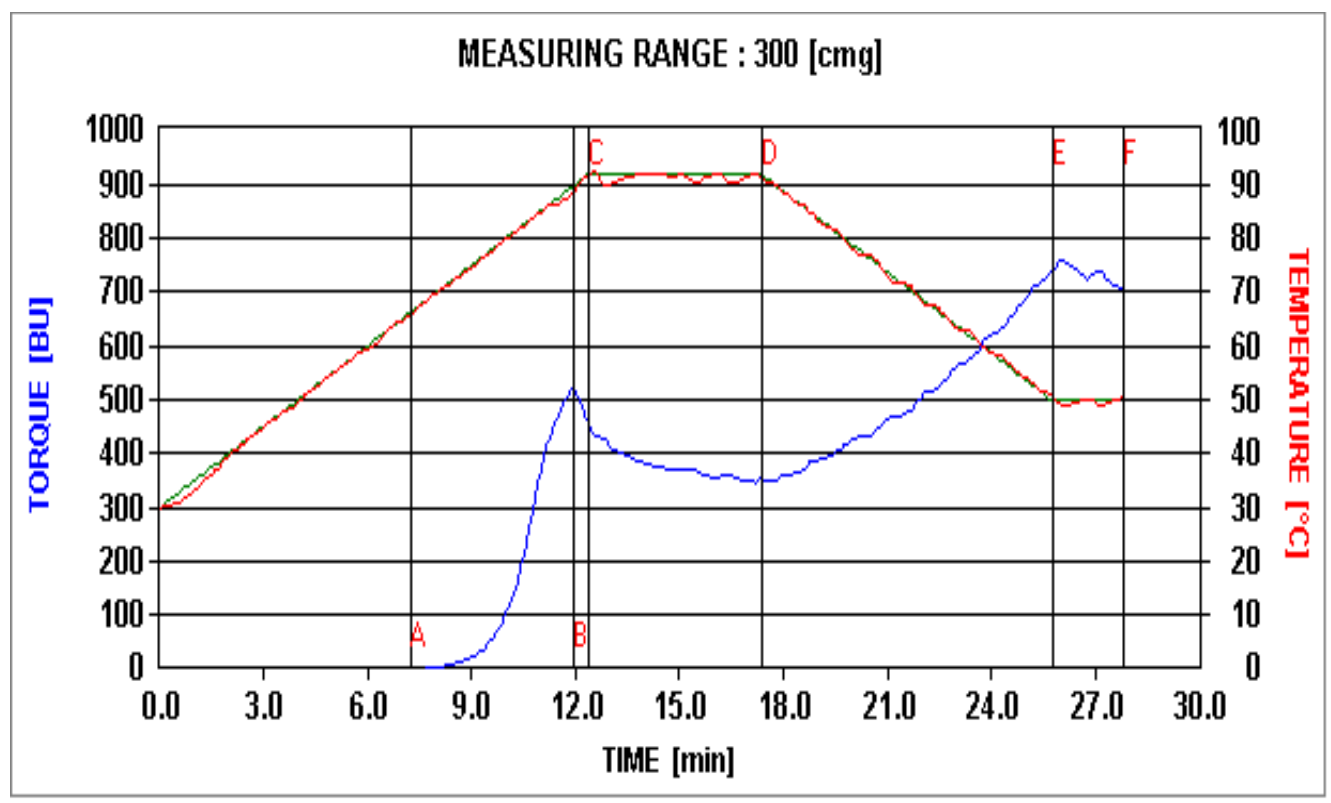


Figure 1a.Pasting profile of sample 1 (100\% wheat flour)

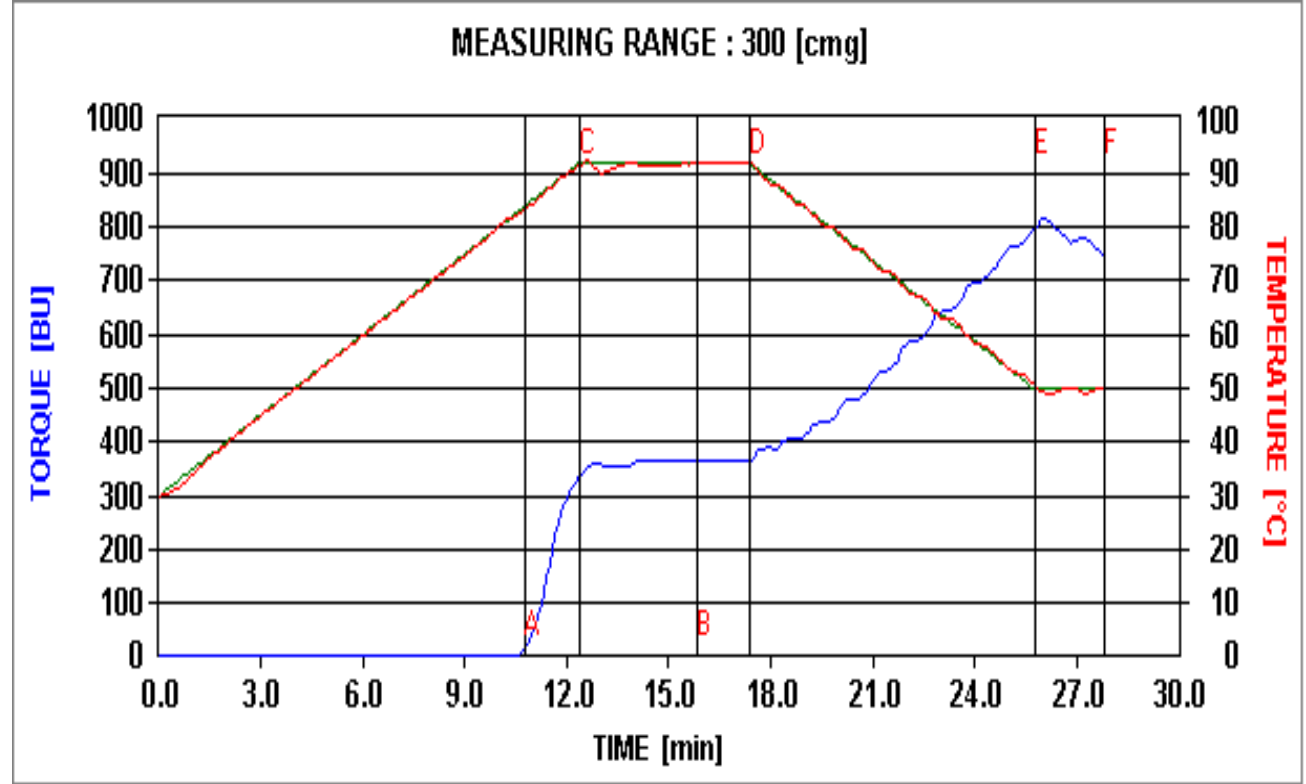

Figure 1b.Pasting profile of sample 2 (50\% wheat $/ 50 \%$ rice flour blend)

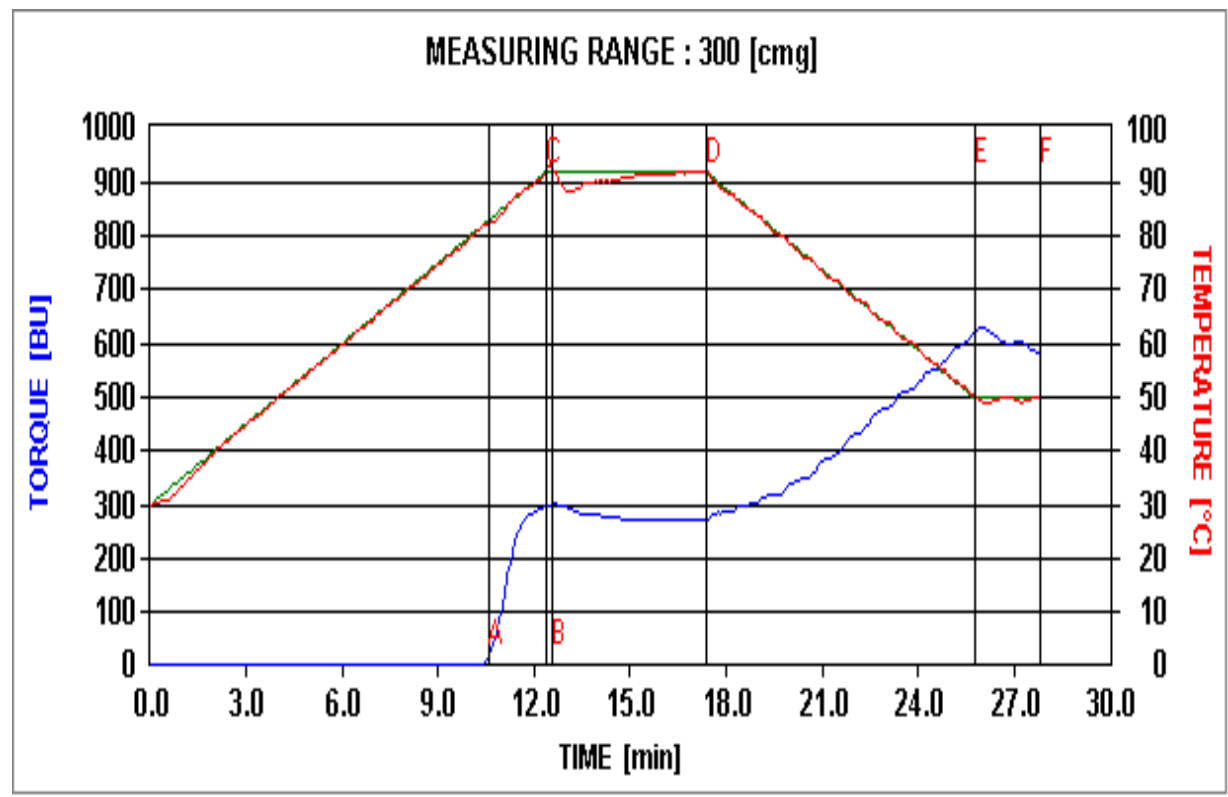

Figure 1c. Pasting profile of sample 3 (50\% wheat/30\% rice/20\% pigeon-pea flour blend) 


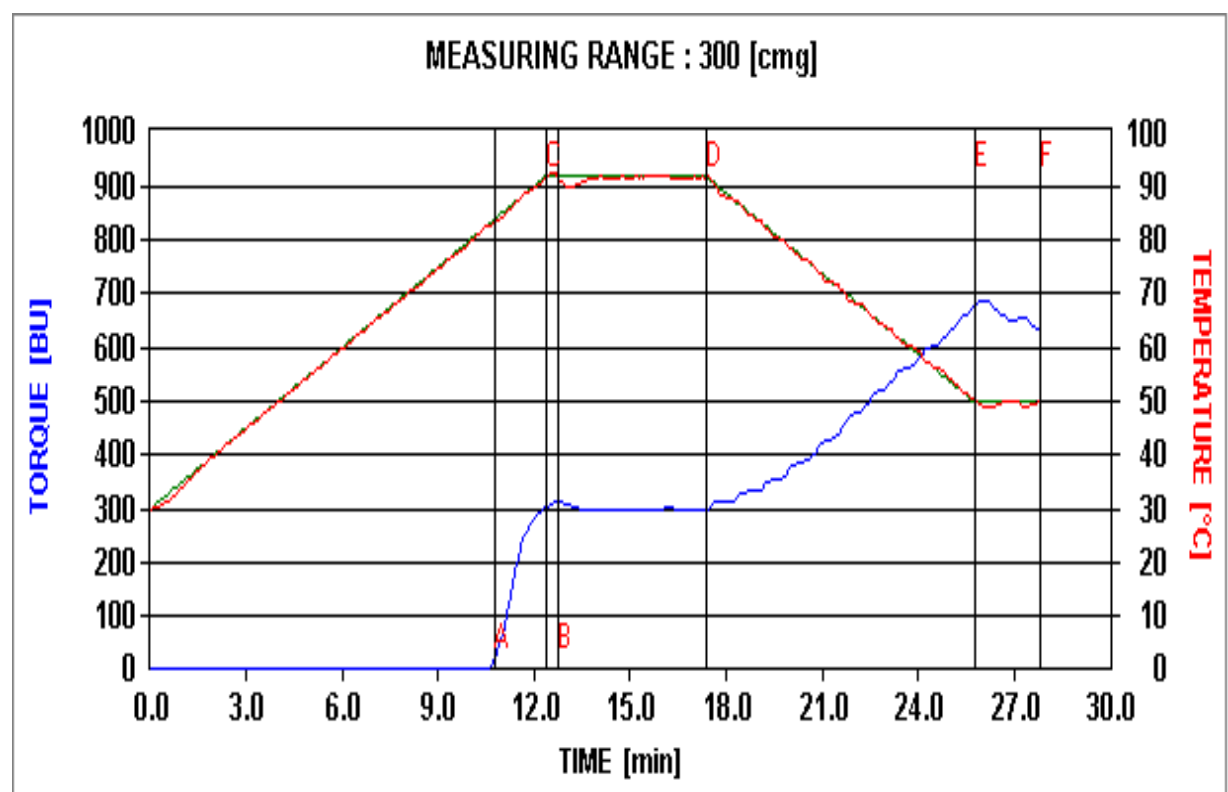

Figure 1d. Pasting profile of sample 4 (50\% wheat $/ 40 \%$ rice $/ 10 \%$ pigeon-pea flour blend)

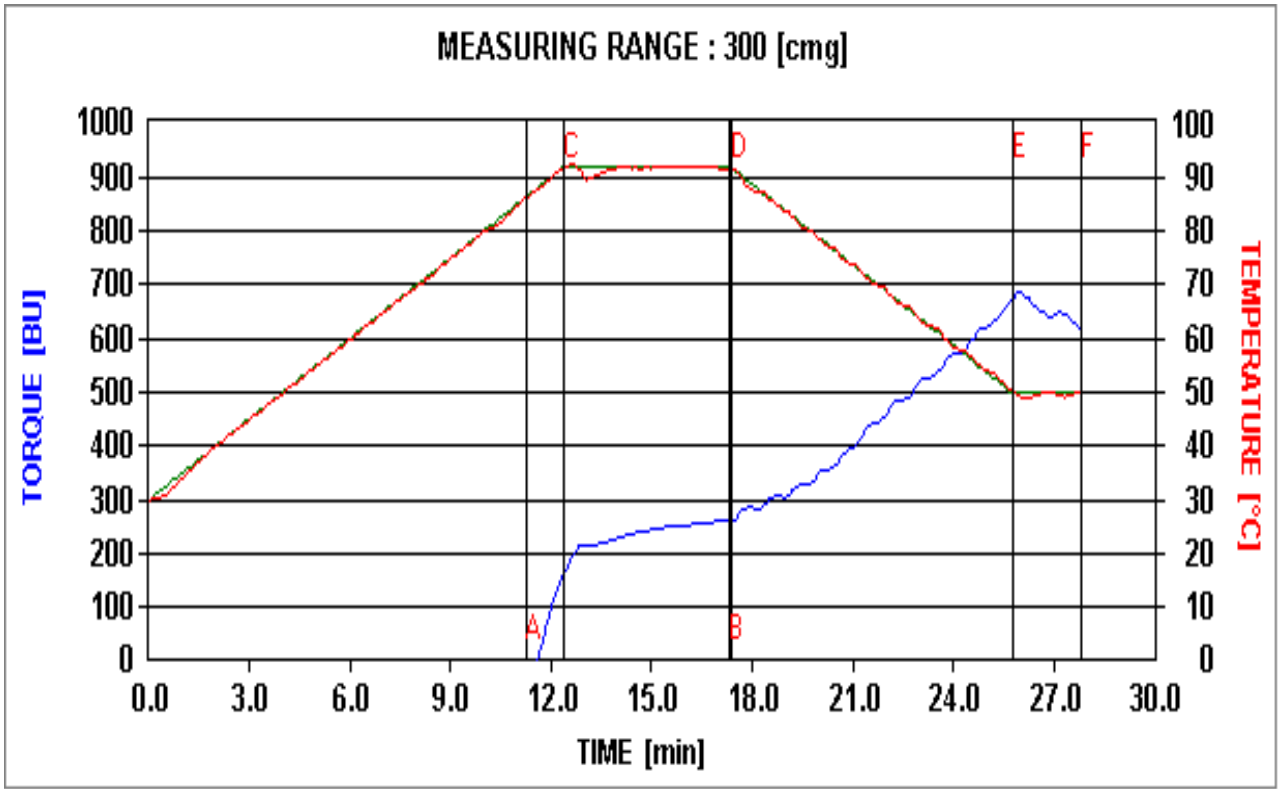

Figure 1e. Pasting profile of sample 5 (30\% wheat $/ 70 \%$ rice flour blend) 


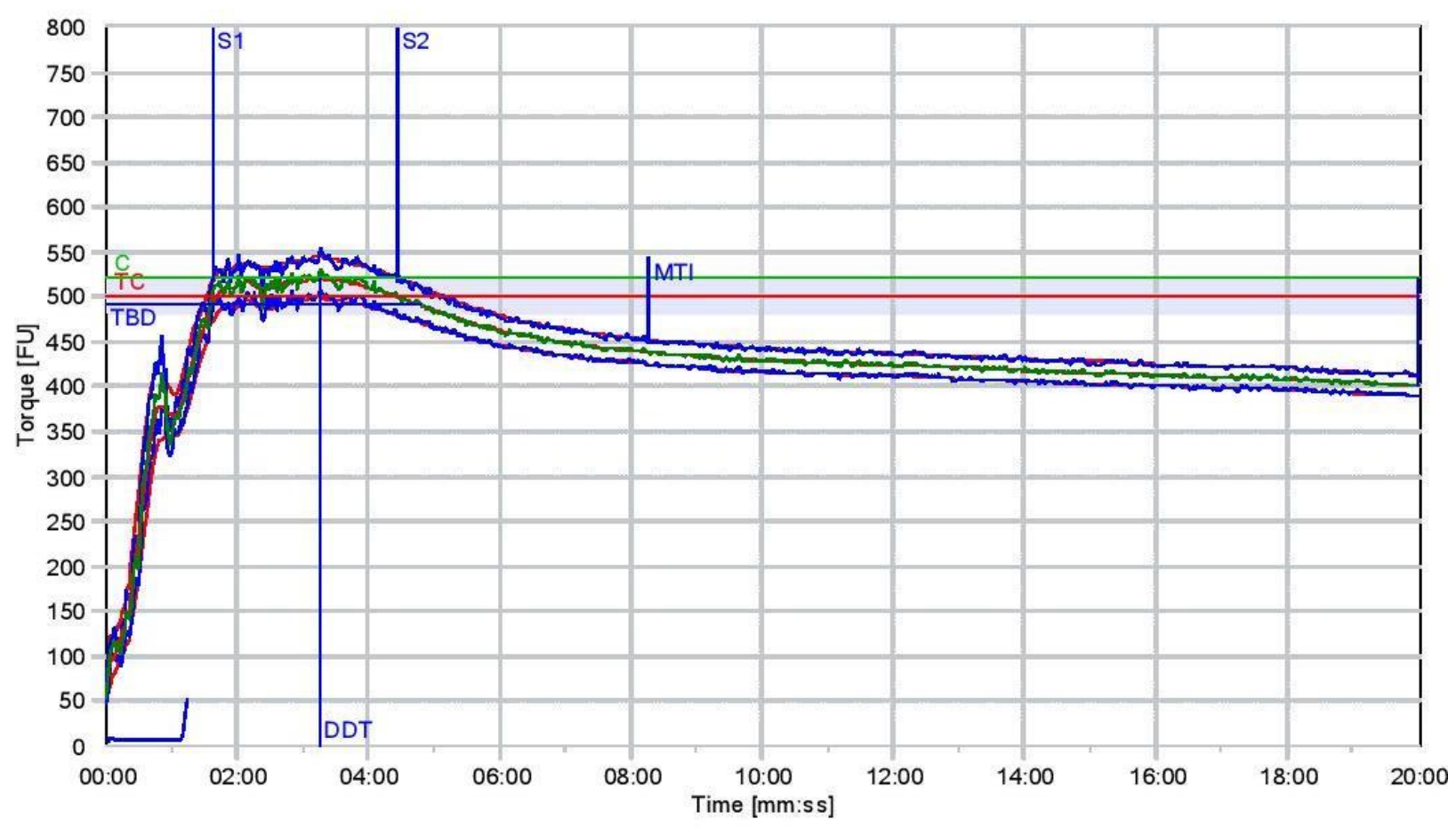

Figure 2a. Farinograph of sample 1 (100\% wheat flour)

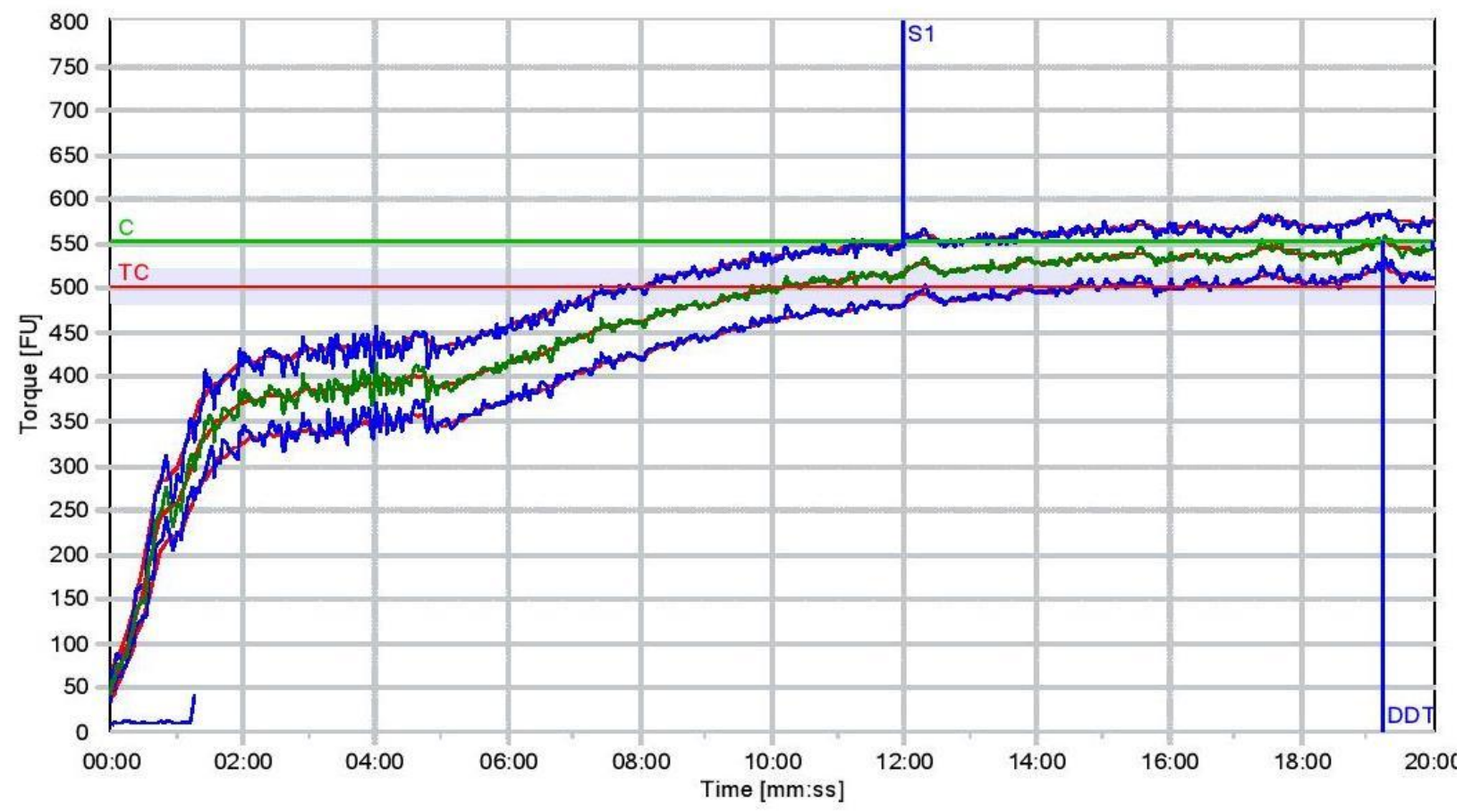

Figure $2 \mathbf{b}$. Farinograph of sample 2 (50\% wheat $/ 50 \%$ rice flour blend) 


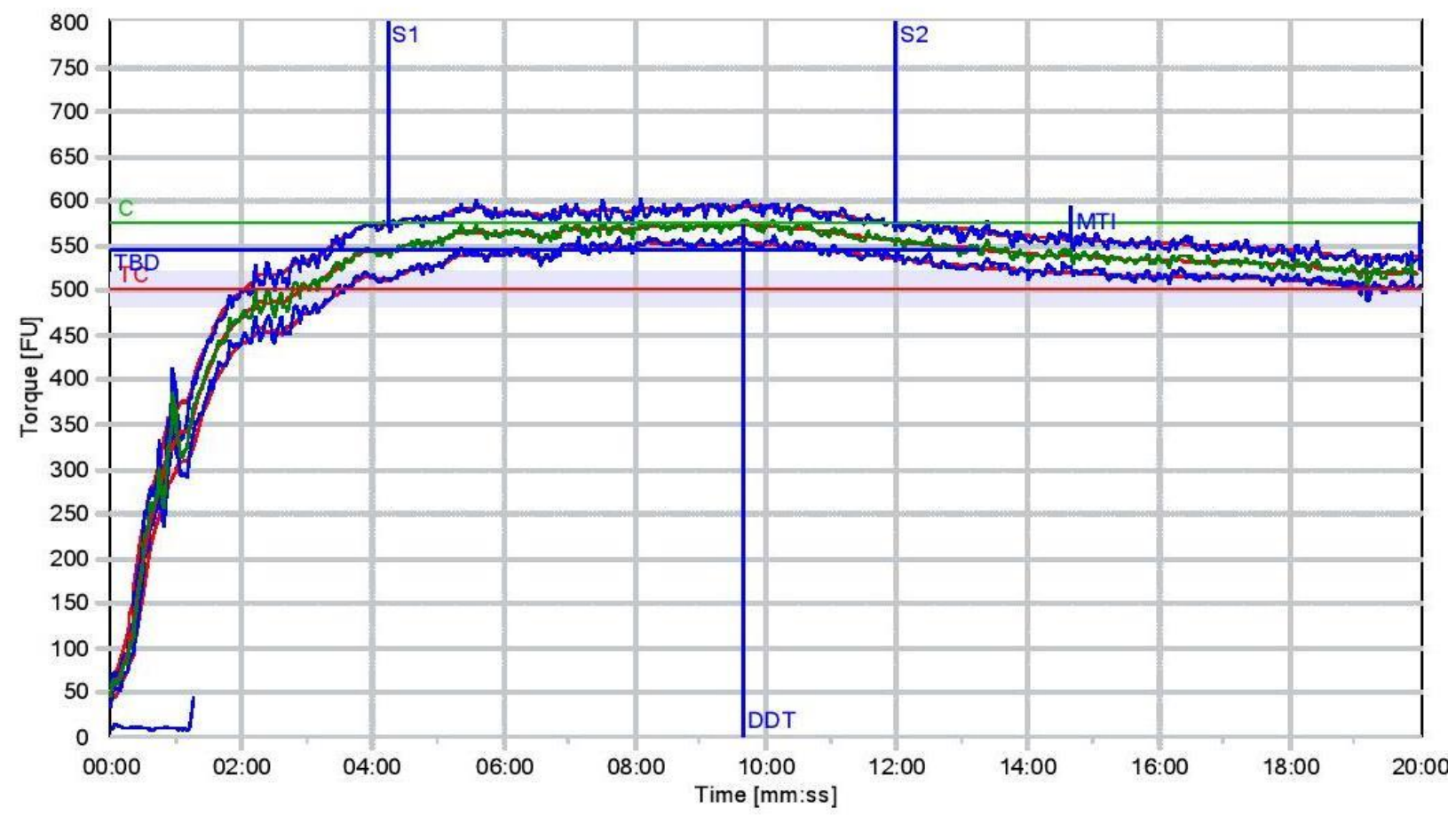

Figure 2c. Farinograph of sample 3 (50\% wheat/30\% rice $/ 20 \%$ pigeon-pea flour blend)

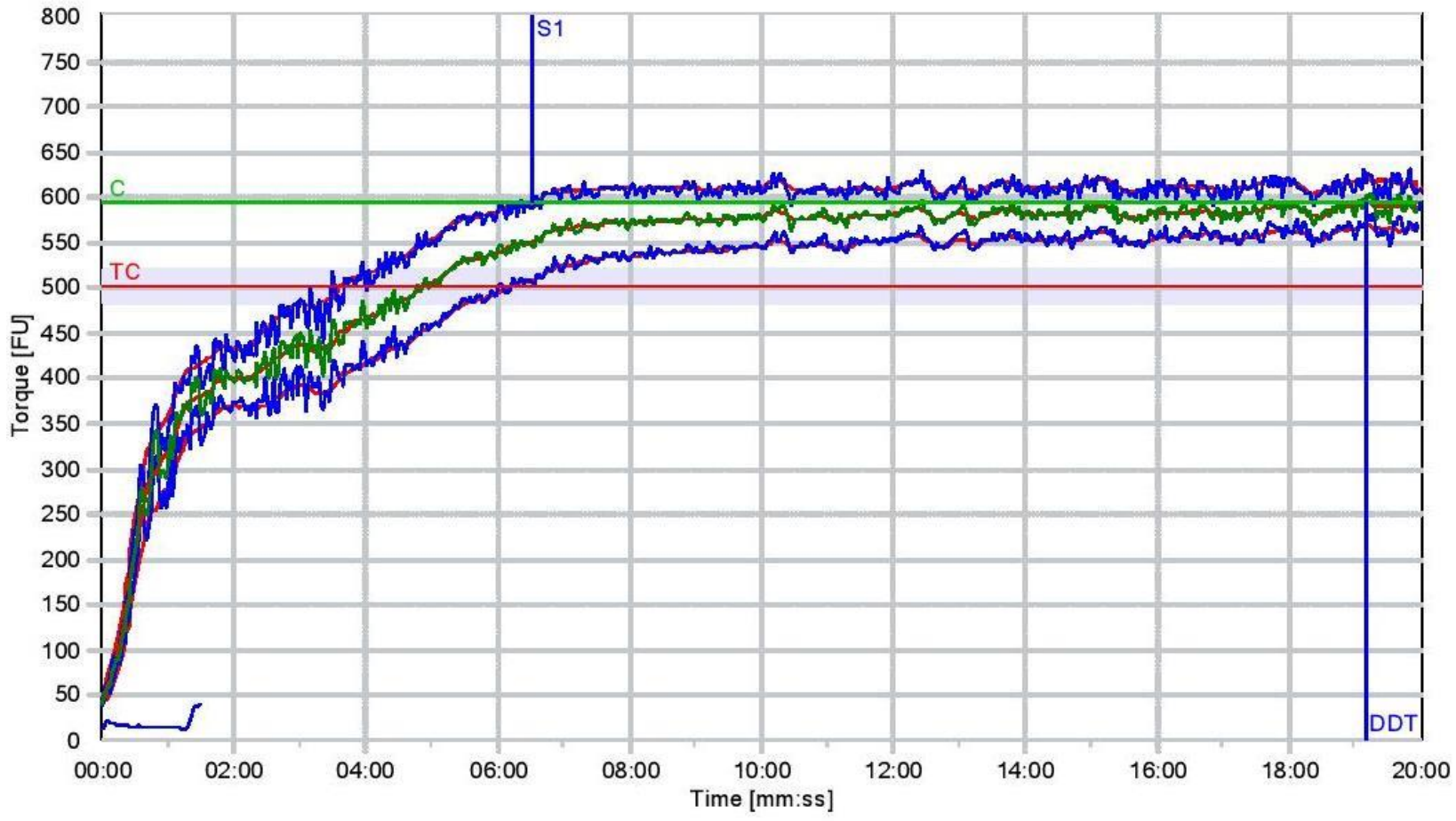

Figure 2d. Farinograph of sample 4 (50\% wheat/40\% rice $/ 10 \%$ pigeon-pea flour blend) 


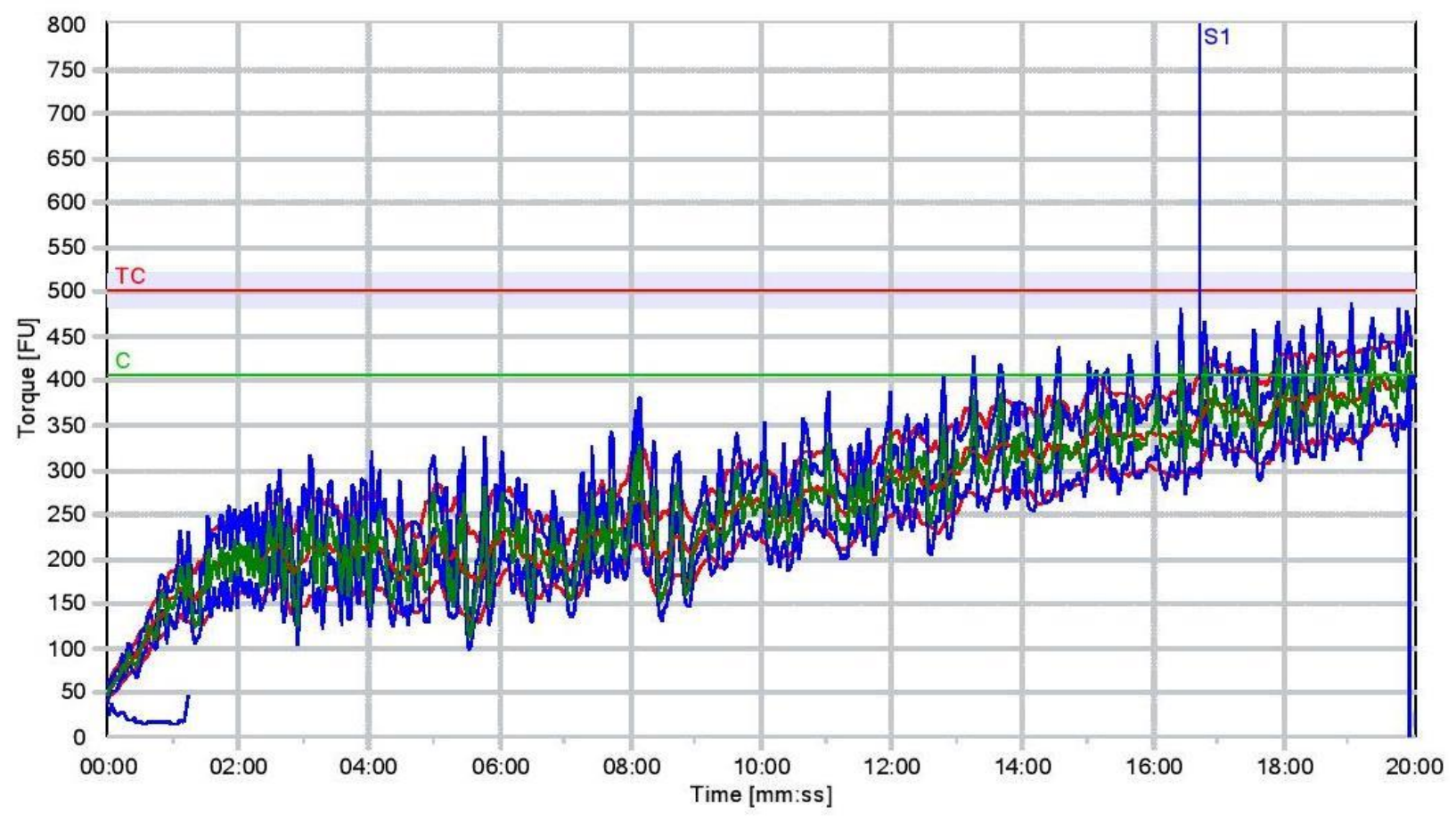

Figure 2e. Farinograph of sample 5 (30\% wheat/70\% rice) 


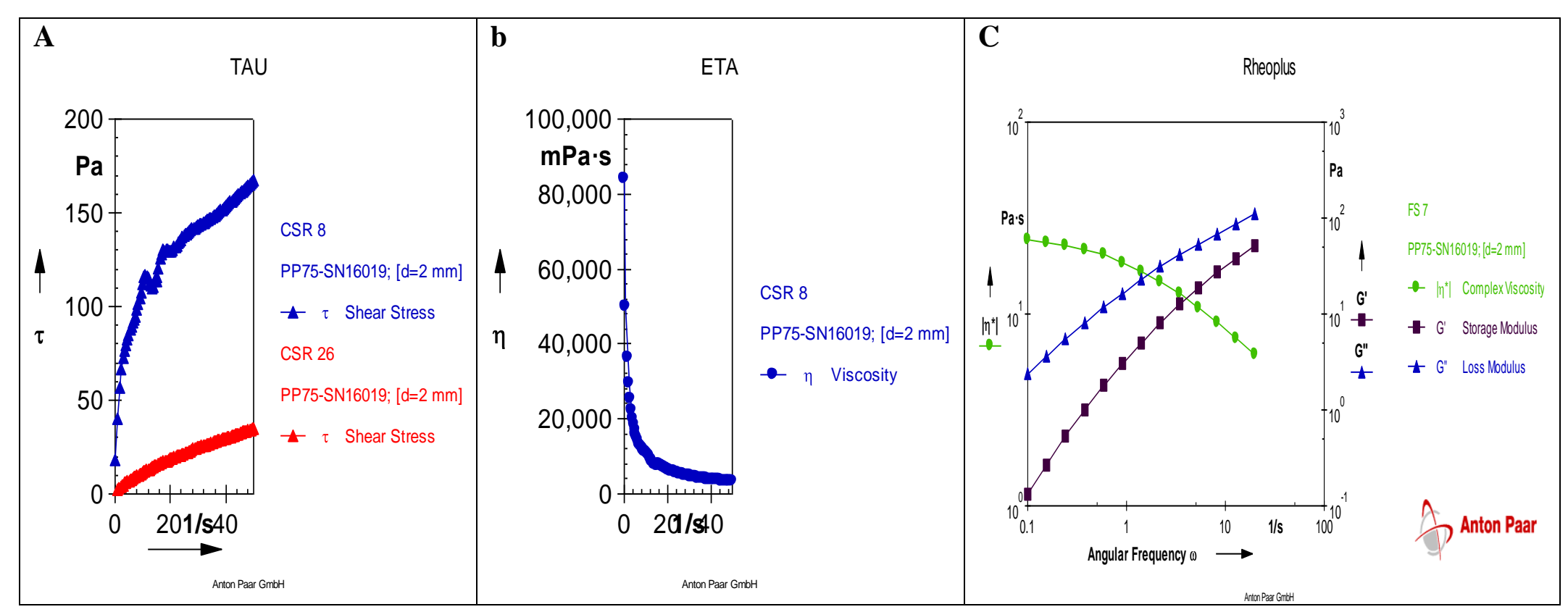

Figure 3. Dynamic rheology of sample 1 (100\% wheat flour) 
Awolu /Carpathian Journal of Food Science and Technology 2019,11(3), 50-68

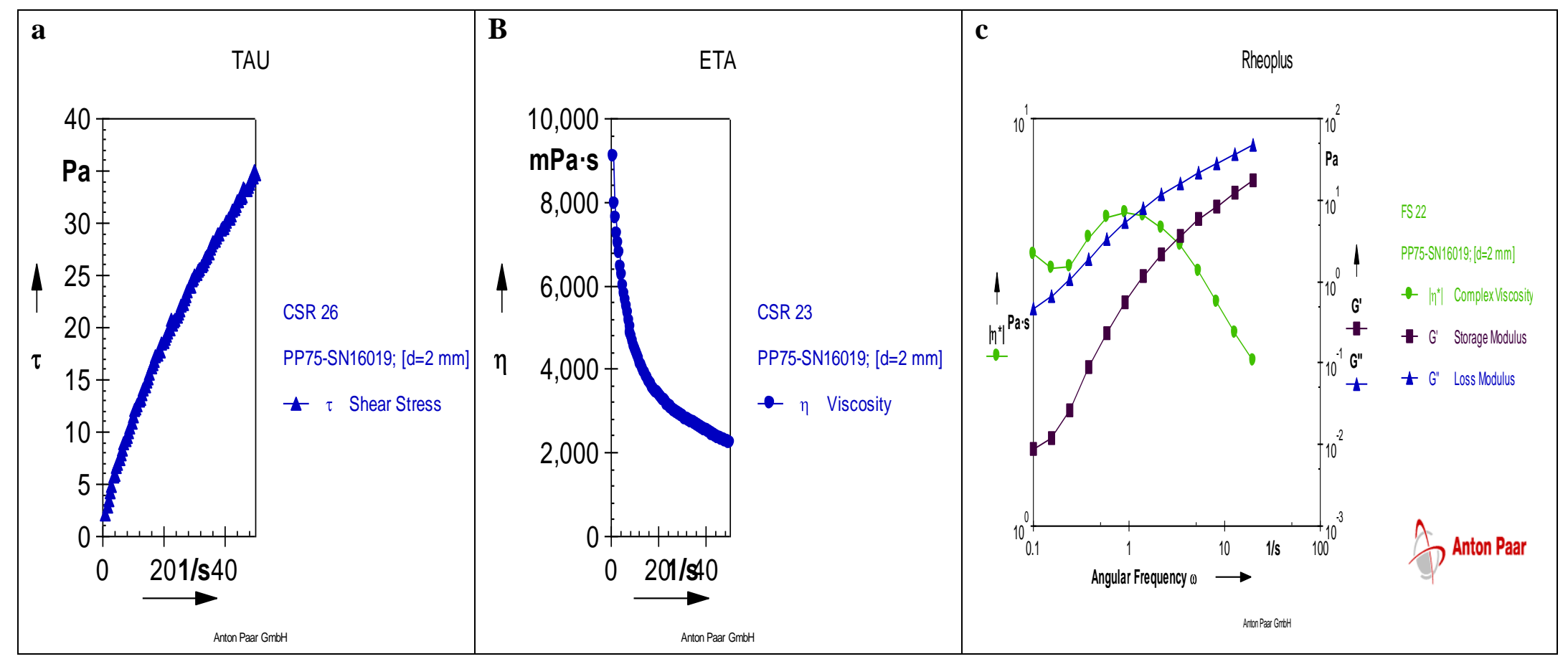

Figure 4. Dynamic rheology of sample 2 (50\% wheat/50\% rice flour blend) 
Awolu /Carpathian Journal of Food Science and Technology 2019,11(3), 50-68

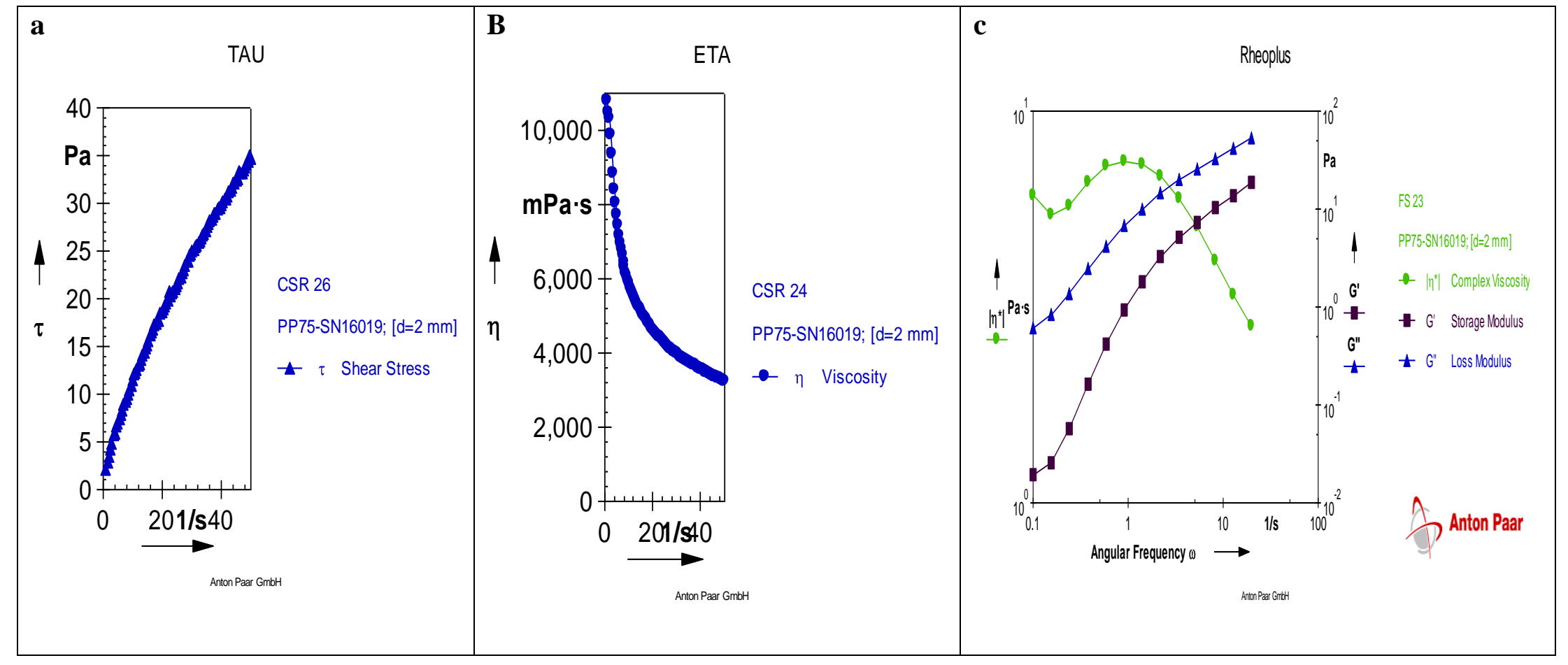

Figure 5. Dynamic rheology of sample 3 (50\% wheat/30\% rice $/ 20 \%$ pigeon-pea flour blend) 
Awolu /Carpathian Journal of Food Science and Technology 2019,11(3), 50-68

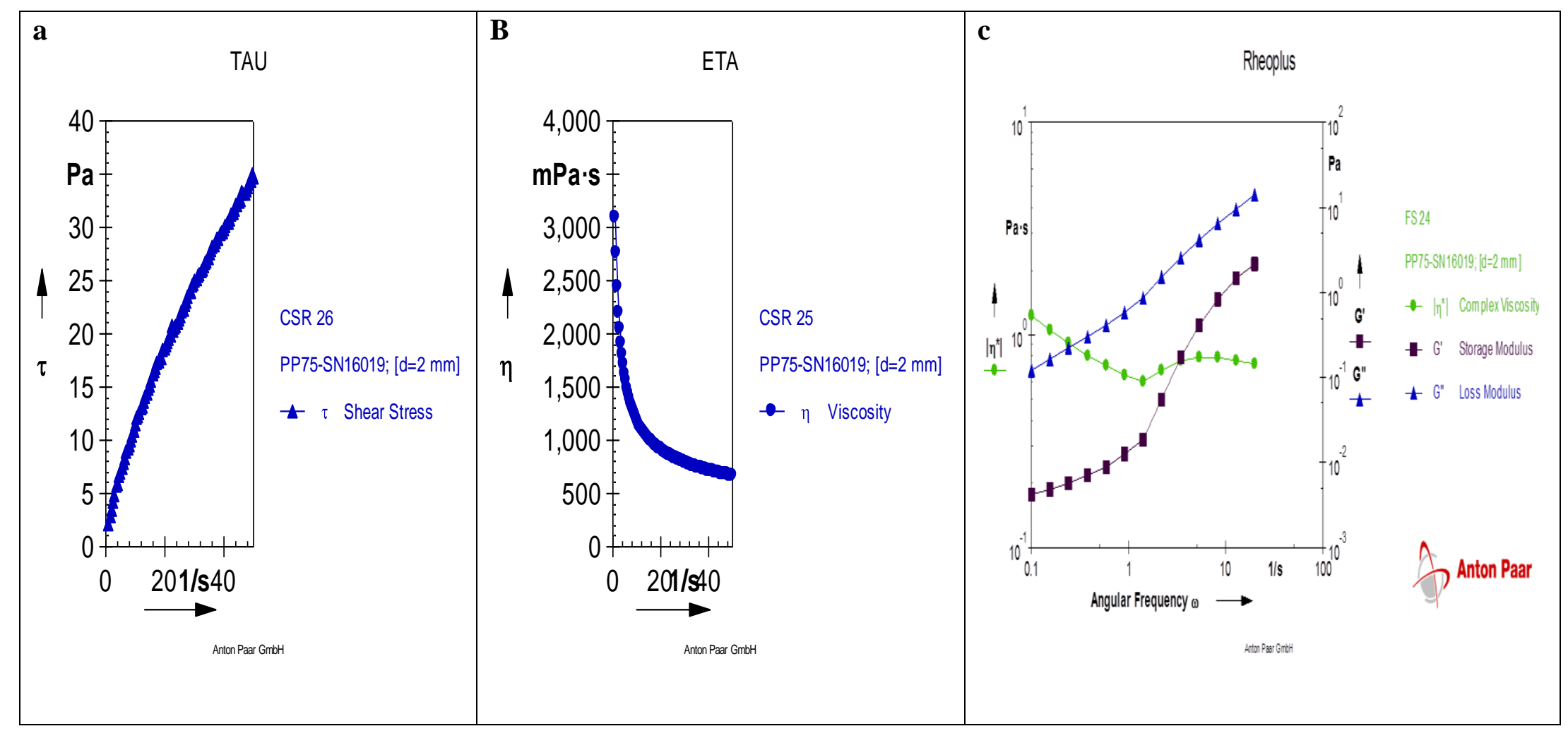

Figure 6. Dynamic rheology of sample 4 (50\% wheat/40\% rice $/ 10 \%$ pigeon-pea flour blend) 


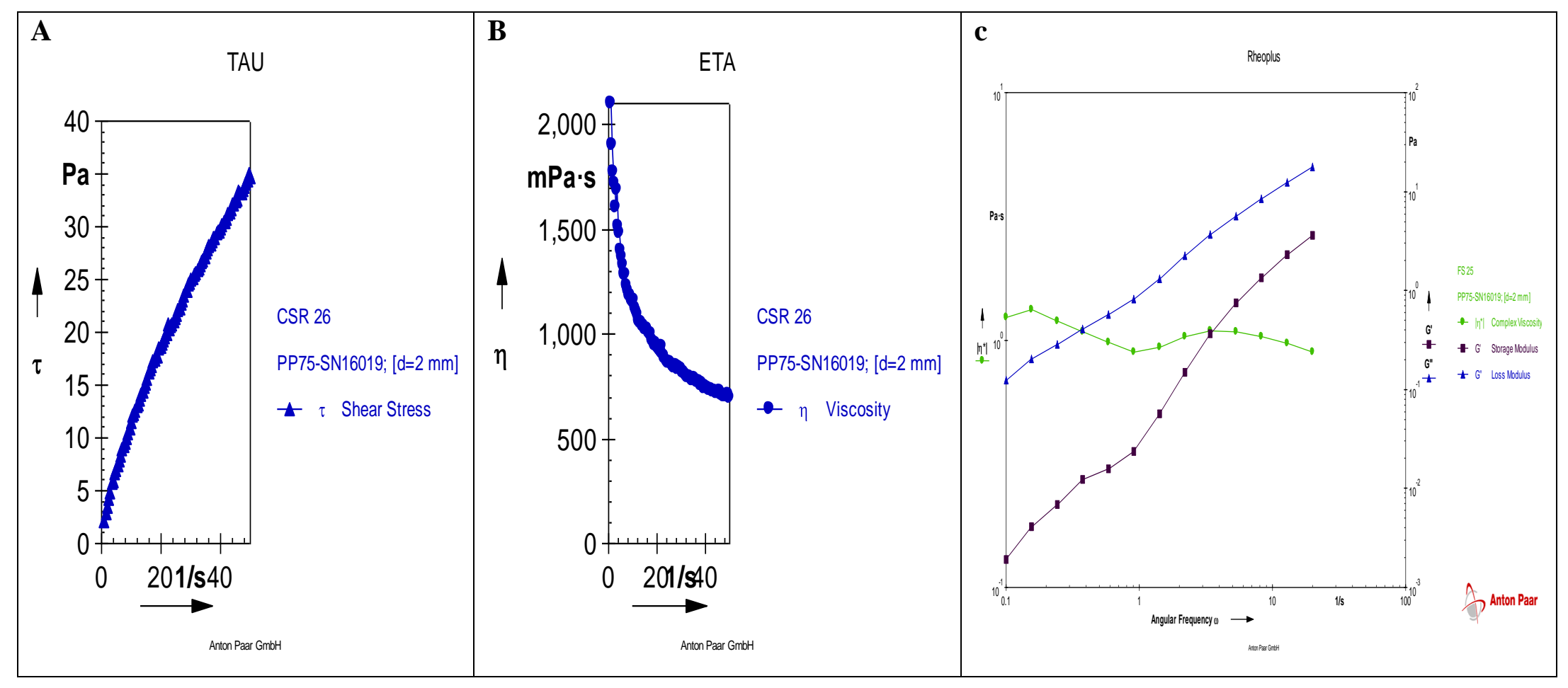

Figure 7. Dynamic rheology of sample 5 (30\% wheat/70\% rice flour blend) 


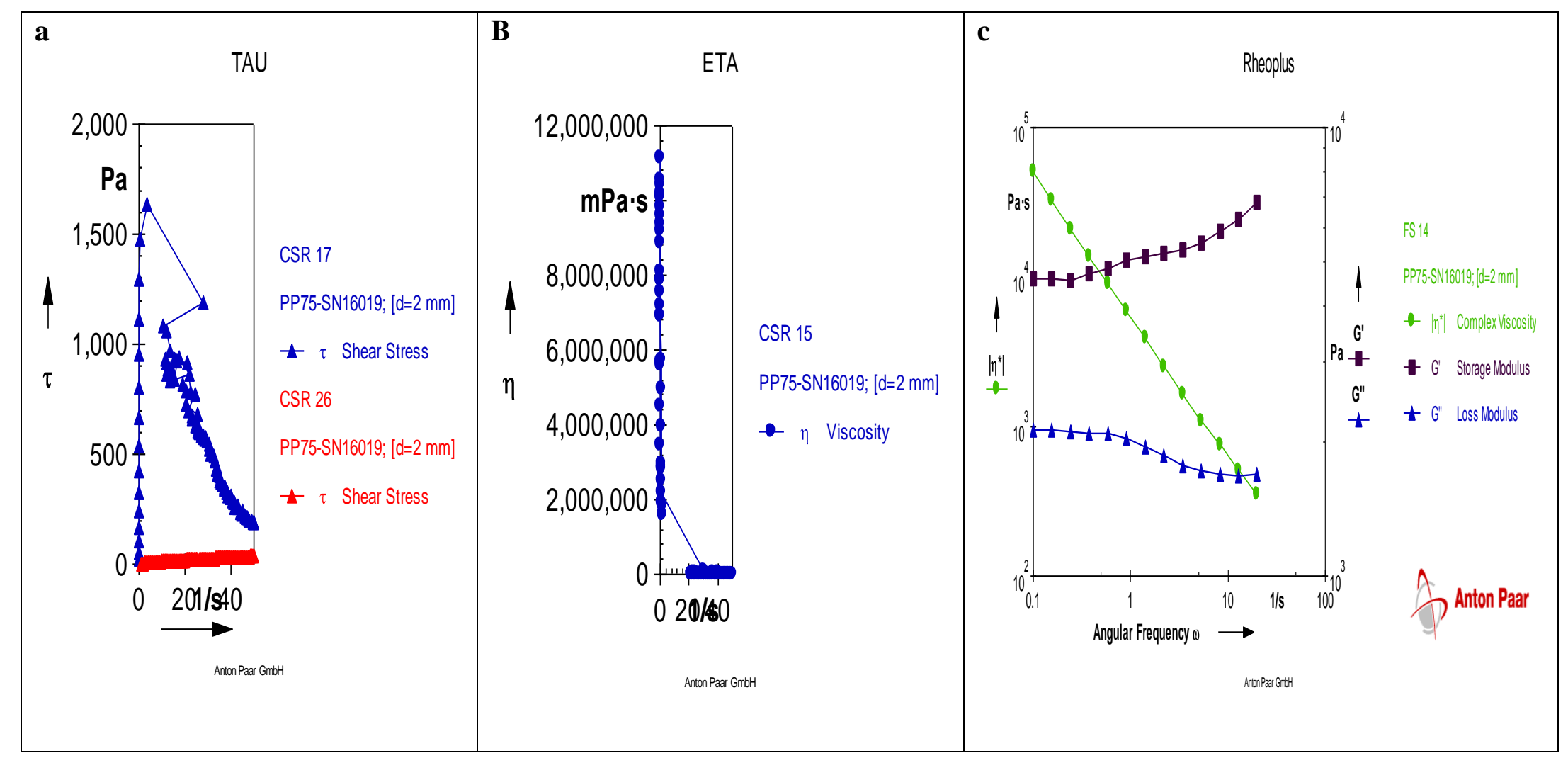

Figure 8. Dynamic rheology of sample $100 \%$ rice flour 


\section{Conclusions}

The potential of the utilization of rice flour as a viable alternative to $100 \%$ wheat flour was reinforced in this study. However, it was established that $100 \%$ rice flour would be inappropriate rheologically. The incorporation of minimum of $20 \%$ pigeon-pea enhanced the farinograph and dynamic rheology properties of composite flour. The results showed that sample 3 as well as blends of wheat-rice with wheat flour component greater than $50 \%$ could be used in bread production. All other blends would be suitable for cookies and snacks production.

\section{References}

AACC. (2000). Approved methods of the AACC (10th ed.). St. Paul, MN: American Association of Cereal Chemists

Adebowale, A.A., Sanni, L.O.., Fadahunsi, E.L. (2011). Functional and pasting properties of cassava-sweet potato starch blends. African Journal of Root Tuber Crops, 9(1), 6-10.

Adegunwa, M.O., Bakare, H.A., Alamu, E.O., Abiodun, O.K. (2012). Processing effects on chemical, functional and pasting properties of cowpea flour from different varieties. Nigeria Food Journal, 30(1), 67-73.

Ahmed, J., Al-Jassar, S., Thomas, L. (2015). A comparison in rheological, thermal, and structural properties between Indian Basmati and Egyptian Giza rice flour dispersions as influenced by particle size. Food Hydrocolloids, 48, 72-83.

Araki, E, Ashida, K., Aoki, N., Takahashi, M., Hamada, S. (2016). Characteristics of rice flour suitable for the production of rice flour bread containing gluten and methods of reducing the cost of producing rice flour. Japan Agricultural Research Quarterly, 50(1), 23-31.

Autio, K., Flander, L., Kinnunen, A., Heinonen, R. (2001). Bread quality relationship with rheological measurements of wheat flour dough. Cereal Chemistry, 78(6), 654657.

Awolu, O. O. (2017). Optimization of the functional characteristics, pasting and rheological properties of pearl millet-based composite flour. Heliyon, 3(2) e00240.

Awolu, O.O., Olarewaju, O.A., Akinade, A.O. (2017). Effect of the addition of pearl millet flour subjected to different processing on the antioxidants, nutritional, pasting characteristics and cookies quality of ricebased composite flour. Journal of Nutritional Health and Food Engineering, 7(2), 00232

Awolu, O.O., Oluwaferanmi, P.M., Fafowora, O.I., Oseyemi, G.F. 2015. Optimization of the extrusion process for the production of ready-to eat snack from rice, cassava and kersting's groundnut composite flours. $L W T$ Food Science and Technology, 64(1), 18-24. Awolu, O.O., Osemeke, R.O., Ifesan, B.O.T. 2016. Antioxidant, functional and rheological properties of optimized composite flour, consisting wheat and amaranth seed, brewers' spent grain and apple pomace. Journal of Food Science and Technology, 53(2), 1151-1163.

Awolu, O.O., Oseyemi, G.F. (2016). Physicochemical and rheological properties of ptimised cocoyam-based composite flour comprising cassava starch. Acta Universitatis Cibiniensis. Series E: Food Technology, 20(2), 65-84.

Baty, J.J., Hwang, H., Ding, Z. (2007). The effect of a carbohydrate and protein supplement on resistance exercise performance, hormonal response, and muscle damage. The Research Journal of the NSCA, 21(2), 321-9.

de la Hera, E., Martinez, M. Gómez, M. (2013). Influence of flour particle size on quality of gluten-free rice bread. LWT Food Science and Technology, 54(1), 199-206.

Demirkesen, I., Mert, B., Sumnu, G., Sahin, S. (2010). Rheological properties of gluten-

Free bread formulations. Journal of Food Engineering, 96(2), 295-303.

Fasoyiro, S.B., Ak, S.R., Arowora, K.A., Sodeko, O.O., Sulaiman, P.O., Olapade, C.O., Odiri, C.E. (2010). Physico-chemical andsensory properties of pigeon pea 
(Cajanuscajan) flours. African Journal of Food Science, 4(3), 120-126.

Helms, S. 2005. Celiac disease and glutenassociated diseases. Alternative Medicine Review, 10(3): 172-192.

Lazaridou, A., Duta, D., Papageorgiou, M., Belc, N., Biliaderis, C.G. (2007). Effects

Li, M., Zhu, K.X., Guo, X.N., Brijs, K., Zhou, H.M. (2014). Natural additives in wheatbased pasta and noodle products: opportunities for enhanced nutritional and functional properties. Comprehensive Reviews in Food Science and Food Safety, 13(4), 347-357.

Liu, X., Wang, C., Liu, L., Zhou, S., Luo, Y. (2015). Rheological properties of the polysaccharide-protein complex from longan (Dimocarpus longan Lour.) pulp. RSC Advances, 5(72), 58663-58668.

Mailhot, W.C., Patton, J.C. (1988). Criteria of flour quality. In: "wheat chemistry and technology". American association of cereal chemists, Inc. Washington State University, Washington, pp 70-81

Mancebo, C.M., San Miguel, M.Á., Martínez, M.M., Gómez, M. (2015). Optimisation of rheological properties of gluten-free doughs with HPMC, psyllium and different levels of water. Journal of Cereal Science, 61, 8-15.

Marco, C., Rosell, C.M. (2008). Functional and rheological properties of protein enriched gluten free composite flour. Journal of Food Engineering, 88(1), 94-103

Martínez, M.M., Calviño, A., Rosell, C.M., Gómez, M. (2014). Effect of different extrusion treatments and particle size distribution on the physicochemical properties of rice flour. Food Bioprocess Technology, 7(9), 2657-2665.

Miś, A., Nawrocka, A. and Dziki, D. 2017. Behaviour of dietary fibre supplements during bread dough development evaluated using novel Farinograph curve analysis. Food Bioprocess Technology, 10(6), 10311041.
Muller, H.G. (1975). Rheology and the conventional bread and biscuit-making process. Cereal Chemistry, 52(3II):89r

Nene, Y.L., Hall, S.D., Sheila, V.K., (1990). Pigeon pea. CAB International, Wallinfork, University Press, Cambridge p.490.

Nozawa, M., Ito, S., Arai, E. (2016). Effect of ovalbumin on the quality of gluten-free rice flour bread made with soymilk. LWT Food Science and Technology, 66, 598-605.

Ocloo, F.C.K., Bansa, D., Boatin, R., Adom, T. and Agbemavor, W.S. 2010. Physicochemical, functional and pasting characteristics of flour produced from Jackfruits (Artocarpus heterophyllus) seeds. Agriculture and Biological Journal of North America, 1(5), 903-908

Oshodi, A.A., Olaofe, O., Hall, G.M. (1985). Amino acid, fatty acid and mineral composition of pigeon pea (Cajanus cajans). International Journal of Food Science and Nutrition, 3,187-191.

Rai, S., Kaur, A., Singh, B. (2014). Quality characteristics of gluten free cookies prepared from different flour combinations. Journal of Food Science and Technology, 51(4), 785-789.

Ronda, F., Pérez-Quirce, S., Angioloni, A., Collar, C. (2013). Impact of viscous dietary fibres on the viscoelastic behaviour of gluten-free formulated rice doughs: a fundamental and empirical rheological approach. Food Hydrocolloids, 32(2),: 252262

Therdthai, N., Tanvarakom, T., Ritthiruangdej, P., Zhou, W. (2016). Effect of microwave assisted baking on quality of rice flour bread. Journal of Food Quality, 39(4), 245254.

Wang, Y.L., Wang, C., Zhou, S., Liu, X. (2016). Thermal and rheological properties of brown flour from Indica rice. Journal of Cereal Science, 70, 270-274.

Weipert, D. (1990). The benefits of basic rheometry in studying dough rheology.Cereal Chemistry, 67(4), 311-317. 
Zecevic, V., Boskovic, J., Knezevic, D., Micanovic, D., Milenkovic, S. (2013) Influence of cultivar and growing season on quality properties of winter wheat (Triticum aestivum L.). African Journal of Agricultural Research, 8(21), 2545-2550 